\title{
Aerosol Single Scattering Albedo retrieval in the UV range: an application to $\mathrm{OMI}$ satellite validation
}

\author{
I. Ialongo ${ }^{1}$, V. Buchard ${ }^{2}$, C. Brogniez ${ }^{2}$, G. R. Casale ${ }^{1}$, and A. M. Siani ${ }^{1}$ \\ ${ }^{1}$ Physics Department, University of Rome, Sapienza, Italy \\ ${ }^{2}$ Laboratoire d'Optique Atmosphérique (LOA), Université des Sciences et Technologies de Lille, France
}

Received: 30 June 2009 - Published in Atmos. Chem. Phys. Discuss.: 14 September 2009

Revised: 18 December 2009 - Accepted: 29 December 2009 - Published: 18 January 2010

\begin{abstract}
The aerosol Single Scattering Albedo (SSA) and Absorbing Aerosol Optical Depth (AAOD) at $320.1 \mathrm{~nm}$ are derived at Rome site by the comparison between Brewer and modelled spectra. The UVSPEC radiative transfer model is used to calculate the UV irradiances for different SSA values, taking into account as input data total ozone and Aerosol Optical Depth (AOD) obtained from Brewer spectral measurements. The accuracy in determining SSA depends on the aerosol amount and on Solar Zenith Angle (SZA) value: SSA uncertainty increases when AOD and SZA decrease. The monthly mean values of SSA and AAOD during the period January 2005-June 2008 are analysed, showing a monthly and seasonal variability. It is found that the SSA and AAOD averages are $0.80 \pm 0.08$ and $0.056 \pm 0.028$, respectively.

AAOD retrievals are also used to quantify the error in the Ozone Monitoring Instrument (OMI) surface UV products due to absorbing aerosols, not included in the current OMI UV algorithm. OMI and Brewer UV irradiances at $324.1 \mathrm{~nm}$ and Erythemal Dose Rates (EDRs) under clear sky conditions, are compared as a function of AAOD. Three methods are considered to investigate on the applicability of an absorbing aerosol correction on OMI UV data at Rome site. Depending on the correction methodology, the bias value decreases from $18 \%$ to $2 \%$ for spectral irradiance at $324.1 \mathrm{~nm}$ and from $25 \%$ to $8 \%$ for EDR.
\end{abstract}

\section{Introduction}

The amount of solar UV radiation reaching the Earth's surface depends on the solar extraterrastrial radiation and transmission properties of the atmosphere. Solar zenith angle, clouds, ozone, aerosols and surface albedo are the predom-

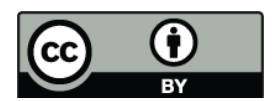

Correspondence to: I. Ialongo (iolanda.ialongo@uniroma1.it) inant factors that interact with UV radiation determining its variability at the surface (Kerr, 2003). While the relationship between total ozone and UV irradiance is well established, based on observations and theory (McKenzie et al., 1999; Zerefos et al., 1995), the role of the above factors is still under study (WMO, 2007). Aerosols play an important role in radiative budget of atmosphere with both direct and indirect effects, by absorbing and scattering the incoming solar radiation (Mallet et al., 2005; Chou et al., 2006) and modifying cloud properties acting as cloud condensation nuclei (Charlson et al., 1992; Schwartz et al., 1996). Atmospheric aerosols can influence UV radiation masking the increase of UV irradiance due to the stratospheric ozone depletion (Meleti and Cappellani, 2000; WMO, 2007).

Aerosol effects on the UV irradiance have been studied by several authors, using both observations and radiative transfer model calculations (Kerr, 1997; Krzyscin and Pulchalski, 1998; Meloni et al., 2003). Nevertheless, the influence of the aerosols has not been fully understood due to their high spatial and temporal variability (Schwartz et al., 1995; Madronich et al., 1998; WMO, 2007). Radiative transfer models can provide the UV irradiance at the Earth's surface under cloud-free conditions with an uncertainty lower than 10\% (Forster et al., 1995; Mayer et al., 1997). Thus, radiative transfer model calculations offers an useful alternative to ground-based and satellite data to estimate surface UV irradiance and aerosol optical properties.

The retrieval of the optical parameters is an important issue of the atmospheric research community (Cheymol et al., 2009). Reuder and Schwander (1999) found that the Single Scattering Albedo, SSA (i.e. the ratio of scattering coefficient to total extinction coefficient), is one of the most important parameter in determining the aerosol effect on UV radiation. The co-albedo, defined as (1-SSA), indicates the fraction of energy absorbed by the aerosols. The Absorbing Aerosol Optical Depth (AAOD) can be derived as the product between the co-albedo and the Aerosol Optical Depth (AOD). 
Several methodologies to determine SSA were developed using global irradiances (Kylling et al., 1998; Kazantzidis et al., 2001). Petters et al. (2003) provided estimates of SSA using measurements of global and diffuse irradiance from an UV multifilter rotating shadowband radiometer and model calculations. Bais et al. (2005) determined the SSA combining the model calculations with measurements of spectral UV irradiances and the AOD by means of Brewer spectrophotometer.

The knowledge of SSA can contribute to the reduction of errors in satellite estimation of surface UV irradiance (Krotkov et al., 1998, 2005; Arola et al., 2005; Kazadzis et al., 2009). Since the network of ground-based UV measurements will inevitably remain sparse, satellite-based UV methods offer a complementary approach to better document the geographical distribution of surface UV irradiance. Surface UV products based on Ozone Monitoring Instrument (OMI) satellite data have been used to monitor the surface UV radiation levels (Levelt et al., 2006; Tanskanen et al., 2006). Nevertheless, the validation of satellite-derived UV products using ground-based measurements is an essential task in order to assess the accuracy of the satellite products. As suggested in several validation studies (Fioletov et al., 2002; Arola et al., 2005; Ialongo et al., 2008; Kazadzis et al., 2009) the overall satellite overestimation of surface UV radiation quantities and hence the observed positive bias, could be attributed to the aerosol absorption mainly in urban boundary layer (Tanskanen et al., 2006; Krotkov et al., 2005). Kazadzis et al. (2009) proposed several correction methodologies for OMI UV products in order to account for the role of absorbing aerosols.

In this work, the aerosol UV scattering and absorption properties derived at Rome site during the period 20052008 using a methodology described by Bais et al. (2005), are analysed. The Single Scattering Albedo and Absorbing Aerosol Optical Depth values are derived at $320.1 \mathrm{~nm}$ by the comparison between Brewer and modelled global irradiances, using ozone amounts and retrieved AOD as input data. The AAOD values are used to determine the aerosol absorption correction to be applied on the OMI UV products (spectral and erythemally weighted irradiances) at Rome site.

\section{Dataset}

\subsection{Ground-based datasets}

The Solar Radiometry Observatory of Sapienza University of Rome $\left(41.9^{\circ} \mathrm{N}, 12.5^{\circ} \mathrm{E}, 75 \mathrm{~m}\right.$ a.s.l.) is located on the roof of the building of Physics Department within the University Campus, in the city centre which is a very populated area, strongly influenced by anthropogenic activity (Meloni et al., 2000). Brewer \#067, operational since 1992, is a Mark IV spectrophotometer with a single-monochromator and it performs scans in the spectral range from 290 to $325 \mathrm{~nm}$ with a stepwidth of $0.5 \mathrm{~nm}$ and a Full band Width at Half Maximum (FWHM) of $0.63 \mathrm{~nm}$ (Casale et al., 2000).

Erythemal Dose Rates (EDR) are obtained by weighting surface spectral UV irradiances with the erythemal action spectrum (CIE, 1987) and by integrating over the wavelength range $290-400 \mathrm{~nm}$. The UV irradiances at wavelengths longer than $325 \mathrm{~nm}$, are extended up to $400 \mathrm{~nm}$ by the Brewer algorithm that applies weighting coefficients to the irradiance at $324 \mathrm{~nm}$ in order to take into account the missing wavelength UV band (Fioletov et al., 2004). The algorithm was developed by Finnish Meteorological Institute (FMI), based on a comparison of synchronous spectral measurements of full range (UVA and UVB) and short range (325-365 nm) instruments during the CAMSSUM-95 campaign in Ispra, May-June 1995 (Tapani Koskela, FMI Helsinki, personal communication).

The retrieval of Aerosol Optical Depth (AOD) from Brewer spectrophotometer was performed using the Langley plot method as described in Sellitto et al. (2006). AODs at $320.1 \mathrm{~nm}$ were retrieved during cloudless days from January 2005 to June 2008. Clear sky days were derived (see Modesti, 2008) from the Cloud Modification Factor, CMF (i.e. the ratio between radiative transfer model calculations under clear sky conditions and actual irradiances provided by the solar radiometer measurements); days with $\mathrm{CMF}>0.95$ were selected as clear sky days.

Periodic checks and tests (monthly, weekly and daily) are carried out in order to guarantee the accuracy and quality of the observations. Brewer \#067 is regularly calibrated by comparison with a travelling reference Brewer by the International Ozone Service (IOS) Inc. Furthermore, the spectrophotometer is intercompared every two years with the travelling standard QASUME spectroradiometer (Gröbner et al., 2005) maintained at the PMOD/WRC (PhysikalischMeteorologisches Observatorium Davos, World Radiation Center, see http://www.pmodwrc.ch/euvc/euvc.html). In this study all UV irradiances were corrected for temperature and cosine effects. The methodology for the temperature correction is described in Siani et al. (2003). The cosine correction was carried out following the methodology described by Gröbner et al. (1996) and Bais et al. (1998). It was based on the angular response, the correction factor for the diffuse component and the ratio between the direct and global UV irradiance. The angular response was determined during Qasume's visit in 2003, showing that UV irradiances were underestimated on average by $9 \%$. To estimate the cosine correction factor, the direct irradiance was modeled using the STAR model (Ruggaber et al., 1994; Schwander et al., 1997) with Rome input settings (Meloni et al., 2000), 50 D.U. (Dobson Units) total ozone steps and SZA ranging between $0^{\circ}$ and $90^{\circ}$ at $1^{\circ}$ steps (Ialongo, 2009). The last comparison with Qasume spectroradiometer in 2008 has shown that, after using cosine and temperature corrected irradiances, the mean ratio Brewer to Qasume is around $+3 \%$ (Hulsen, 2008). 


\subsection{OMI UV products}

Ozone Monitoring Instrument (OMI) onboard the NASA EOS Aura space-craft (on flight from 14 July 2004), is a nadir viewing spectrometer that measures solar reflected and backscattered light in the spectral range from $270 \mathrm{~nm}$ to $500 \mathrm{~nm}$ with an average spectral resolution of $0.5 \mathrm{~nm}$. The Aura satellite describes a sun-synchronous polar orbit, crossing the equator at 13:45 local time. The width of the instrument's viewing swath (consisting of 60 individual pixels) is $2600 \mathrm{~km}$ and it is large enough to provide global daily coverage with a spatial resolution at nadir of $13 \times 24 \mathrm{~km}$. OMI products include ozone columns, aerosols, clouds, surface $\mathrm{UV}$ irradiance and trace gases $\left(\mathrm{NO}_{2}, \mathrm{SO}_{2}, \mathrm{HCHO}, \mathrm{BrO}\right.$, and OClO) (Levelt et al., 2006).

OMI surface UV retrievals are determined by means of an extension of the TOMS UV algorithm developed by NASA Goddard Space Flight Center (GSFC) (Herman et al., 1999; Krotkov et al., 1998, 2002; Tanskanen et al., 2006). Firstly, the algorithm estimates the surface irradiance under clear-sky conditions ( $\left.E_{\text {clear }}\right)$ using as input OMI-derived total ozone and climatological surface albedo (Tanskanen, 2004). Afterwards the clear sky irradiance is adjusted by a satellite derived cloud/non absorbing aerosol transmittance factor $C_{T}$ in order to determine actual surface irradiance $\left(E_{\text {cloud }}\right)$ as follows:

$E_{\text {cloud }}=E_{\text {clear }} \cdot C_{T}$.

Krotkov et al. (1998) described in details the model and the assumptions used in the determination of clear-sky irradiances. They concluded that in absence of clouds, aerosols, and snow cover, the satellite estimates of the surface UV can have accuracies comparable to the ground-based measurements.

The current OMI surface UV algorithm does not include absorbing aerosols, therefore OMI UV data are expected to show an overestimation for regions affected by absorbing aerosols (for example urban site). Moreover, since these aerosols also attenuate the outgoing shortwave radiation, the UV algorithm further increases the error, causing an overestimation of UV irradiance, especially in the summertime (Arola et al., 2005; Tanskanen et al., 2007).

The OMI UV collection 3 of EDR and spectral irradiances at $324.1 \mathrm{~nm}$ at local solar noon and at overpass time were analysed in this work.

\subsection{Radiative transfer modelling}

The UVSPEC model (Mayer et al., 1997; Mayer and Kylling, 2005) from the LibRadTran package version 1.2 was used to determine the global spectral UV irradiances at different SSA values ranging from 0.60 to 0.99 , with a step of 0.01 . UVSPEC solves the radiative-transfer equation using the pseudo-spherical discrete ordinates algorithm (Stamnes et al., 1988) running with 16 streams. Irradiance spectra were calculated at $0.1 \mathrm{~nm}$ steps and then they were convoluted with the slit function of the Brewer \#067 with a FWHM of $0.63 \mathrm{~nm}$.

The atmospheric composition used in the model is based on Brewer measured parameters (total ozone, AOD at $320.1 \mathrm{~nm}$ ) and their standard profiles. The AFGL (Air Force Geophysics Laboratory) mid-latitude profiles were used for ozone, temperature and air pressure (Anderson et al., 1986). Ozone profiles were rescaled to match the ozone column measured at Rome. The aerosol vertical distribution provided by the Elterman (1968) profile was scaled to match the measured optical depth at $320.1 \mathrm{~nm}$. An asymmetry parameter of 0.7 at $320 \mathrm{~nm}$ was assumed to be constant with altitude for all days selected for this work (Bais et al., 2005). Following the procedure of Tanskanen (2004), a climatological surface albedo of 0.05 was used and assumed constant in the entire UV spectral region.

The high-resolution ATLAS 3 extraterrestrial solar spectrum was used in the model calculations with a wavelength step of $0.05 \mathrm{~nm}$. Sun-Earth distance correction (Spencer et al., 1971) was applied to the extraterrestrial spectrum.

\section{Single Scattering Albedo retrieval}

The Single Scattering Albedo (SSA) represents a key parameter in describing the aerosol optical properties. The SSA describes the portion of solar radiation scattered from the main beam passing through the atmosphere. The SSA influences the diffuse radiation, while its effect on direct radiation can be considered negligible. Theoretically, SSA values can vary between 0 (totally absorbing aerosol) and 1 (totally scattering aerosol). Actual SSA values are ranging from 0.5 to 1.0 in the visible and UV wavelengths.

Model calculations can be used for retrieving SSA when global or diffuse spectral irradiance, Solar Zenith Angle (SZA), total ozone and AOD are known. The accuracy of the retrieved SSA depends on the sensitivity of the radiation quantities to the SSA variations, but it is also affected by the measurements' accuracy and the detection limit of the instruments at low-intensity conditions (i.e. large SZAs, small wavelengths, high-AOD). Bais et al. (2005) described a method for deriving SSA values combining model calculations and Brewer spectral irradiance measurements.

In the present work, this methodology was applied to determine the SSA from Brewer irradiances at $320.1 \mathrm{~nm}$ during clear sky days from 2005 to 2008 at Rome site. The Brewer global irradiances at $320.1 \mathrm{~nm}$ were compared with UVSPEC modeled irradiances taking into account SZA and the AOD at $320.1 \mathrm{~nm}$, derived from Brewer measurements each $30 \mathrm{~min}$ during the day. The daily mean total ozone column data provided by Brewer direct sun measurements were included also as input in the model.

The SSA value for which the modeled and measured irradiances agree to better than $1 \%$, can be determined. 
Depending on the sensitivity of the global irradiance to SSA variations, many SSA values could satisfy such condition. The number of SSA values is an indicator of the accuracy in estimating SSA. Since global UV irradiance is not very sensitive to changes in SSA, the uncertainty of the SSA retrieval from global UV irradiance measurements can be quite large (from 0.05 to 0.15 ).

Uncertainties in both the irradiance measurements and the model input parameters contribute to the overall uncertainty of the methodology. The uncertainty of Brewer UV irradiance is estimated to be $5 \%$, while the overall uncertainty of the modeled global irradiance is $4.6 \%$ (Bais et al., 2005). According to the results provided by Bais et al. (2005), the uncertainties on SSA retrievals derived by global UV irradiances with overall accuracy (derived from the calibration) in the order of $5 \%$, can vary from \pm 0.05 (for high AOD and SZA values) to \pm 0.15 (for low AOD and SZA values) due to the sensitivity of this methodology. Assuming the error in $\mathrm{AAOD} \approx \delta \mathrm{SSA} \cdot \mathrm{AOD}$ (Arola et al., 2005), the uncertainty on the estimated AAOD can vary from 0.020 (high aerosol load) to 0.026 (low aerosol load).

The SSA daily evolution obtained by comparing global irradiance measurements with model calculations is shown in Fig. 1. The different points in single hourly SSA retrieval are calculated using the $1 \%$ model/measurement accuracy matching. Two examples of the retrieved results are given for two cloud-free days with different aerosol load. The first day (28 April 2008) has an AOD daily mean of 0.15 while the second day (7 August 2007) is characterized by an higher aerosol content $(\mathrm{AOD}=0.29)$. The low aerosol content during 28 April has reduced significantly the accuracy of the retrieved SSA value (upper panel in Fig. 1). The dispersion of SSA value for the low AOD day can reach the value 0.05; otherwise, a maximum dispersion of 0.02 can be observed during the day with the higher aerosol load (lower panel in Fig. 1). The same results were found by Bais et al. (2005). No such a clear difference in SSA dispersion is observed at different hours during the day, showing that the accuracy on SSA retrieval is slightly affected by SZA variations.

Figure 2 shows the variability within each month and between different months of SSA (upper panel) and AAOD (lower panel), derived from Brewer global UV irradiance measurements for the period January 2005-June 2008. The error bars refer to one standard deviation of the monthly means. The SSA average over this period is $0.80 \pm 0.08$ while the AAOD average is $0.056 \pm 0.028$, where the uncertainties are given as one standard deviation. The SSA and AAOD monthly means show a significant variability within each month; a seasonal variation in SSA can be observed, with lowest values in winter and increasing in summer and in early autumn. Otherwise, a seasonal variability in AAOD monthly means is not evident. The annual pattern of AAOD (Fig. 2) is included within the limits of the $0.02-0.026$ uncertainty that is reported.
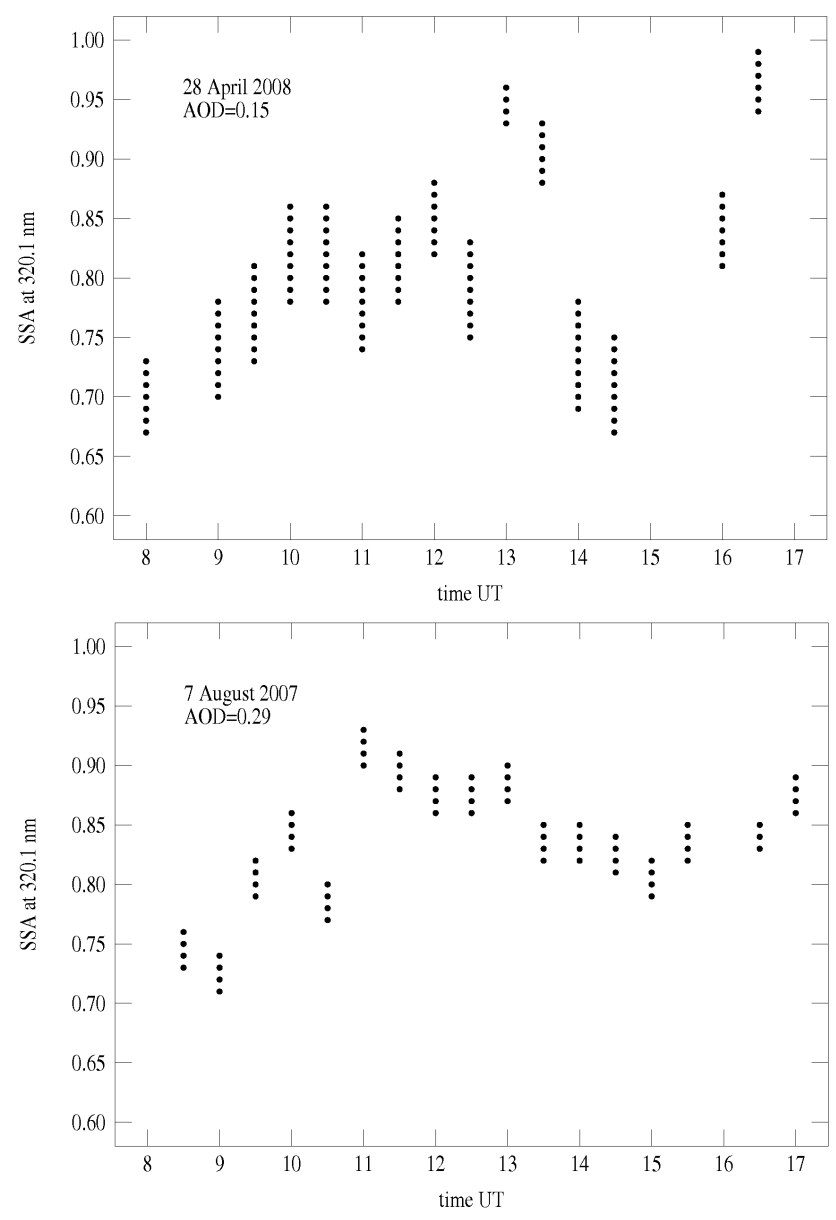

Fig. 1. SSA daily evolution obtained by comparing global irradiance measurements with model calculations, during 2 days with low (28 April 2008) and high (7 August 2007) aerosol content.

\section{OMI UV data validation: the role of absorbing aerosols}

The SSA and AAOD at $320.1 \mathrm{~nm}$ were retrieved at Rome site using the methodology described in Sect. 3. The relative differences (OMI-Brewer)/Brewer irradiance at $324.1 \mathrm{~nm}$ and EDR at overpass time are plotted against AAOD in Fig. 3 (upper and lower panel, respectively). It can be noticed that the bias increases with increasing AAOD, since OMI algorithm does not properly account for the absorbing aerosols in the boundary layer. The regression equations were estimated, showing for AAOD larger slopes $(S>1.3)$ and higher correlation coefficient values $(r>0.38)$ than those obtained for AOD $(S<0.3$ and $r<0.3)$ (not shown). Thus, AAOD is the most appropriate quantity to evaluate the effect of aerosol on the OMI products.

Based on the above results, OMI UV data can be post-corrected using measurements of SSA and AOD in the UV range and the regression coefficients 

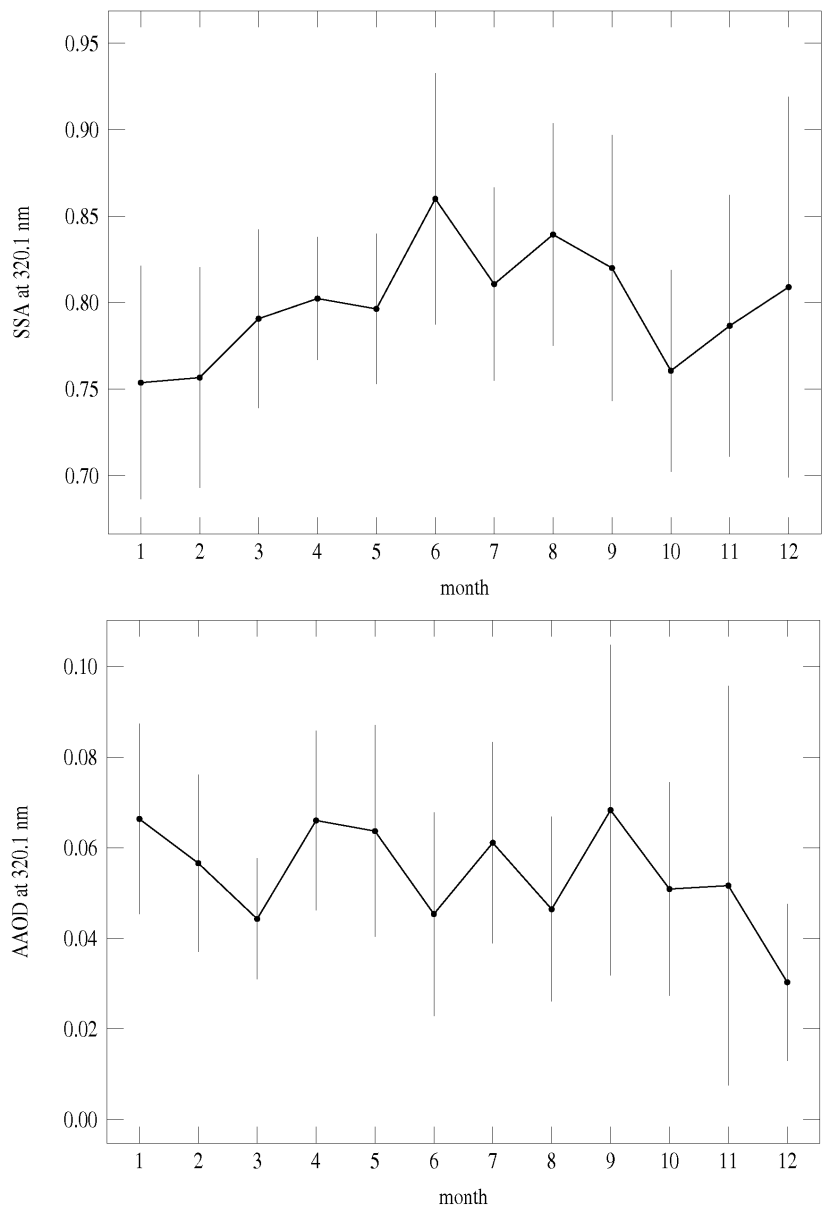

Fig. 2. Monthly mean SSA (top) and AAOD (bottom) at $320.1 \mathrm{~nm}$ during the period January 2005-June 2008 with one standard deviation bars.

between (OMI-Brewer)/Brewer and AAOD. According to the methodology described by Kazadzis et al. (2009), the slope can be used to determine the aerosol absorption correction factor $C_{A}$, which can be applied to OMI UV irradiance ( $E_{\text {cloud }}$ in Eq. 1$)$ as follows:

$E_{\text {corr }}=E_{\text {cloud }} \cdot C_{A}=E_{\text {clear }} \cdot C_{T} \cdot C_{A}$

where $E_{\text {corr }}$ represents the post-corrected OMI UV product. $C_{A}$ is defined to be equal to unity in case of non-absorbing aerosols (sulfate, sea salt) and less than unity in case of absorbing aerosols (i.e. dust, carbonaceous, pollution).

According to Kazadzis et al. (2009), $C_{A}$ can be obtained using three methods.

Method 1: $C_{A}=(1+S \cdot \mathrm{AAOD})^{-1}$

In the first method, the slope $S$ was derived from the linear regression between the relative difference (OMIBrewer)/Brewer and AAOD.

Method 2: $C_{A}=(1+S \cdot \text { AAODS })^{-1}$
Table 1. Results of the correction for absorbing aerosol of OMI UV data. SD indicates Standard Deviation. The bias is calculated as [(OMI-Brewer)/Brewer] $* 100 \%$. $S$ indicates the slope estimated from linear regressions.

\begin{tabular}{llcccccc}
\hline & \multicolumn{3}{c}{ overpass } & \multicolumn{3}{c}{ noon } \\
$\# \quad$ & $C_{A}^{-1}$ & $S$ & bias & $\mathrm{SD}$ & $S$ & bias & $\mathrm{SD}$ \\
\hline Irradiance at 324 nm & & & & & & \\
- & 1 & - & 17.7 & 10.2 & - & 15.0 & 7.9 \\
1 & $1+S$.AAOD & 1.32 & 9.9 & 9.1 & 1.60 & 5.4 & 5.9 \\
2 & $1+S \cdot A A O D S$ & 1.64 & 5.8 & 7.4 & 1.44 & 4.3 & 5.4 \\
3 & $1+3 \cdot$ AAOD & 3 & 1.6 & 9.7 & 3 & -2.0 & 6.7 \\
\hline EDR & & & & & & \\
- & 1 & - & 25.0 & 10.7 & - & 25.8 & 10.1 \\
1 & $1+S \cdot A A O D$ & 1.80 & 14.3 & 8.1 & 1.60 & 14.5 & 6.7 \\
2 & $1+S \cdot A A O D S$ & 2.05 & 9.6 & 6.5 & 1.24 & 14.7 & 6.3 \\
3 & $1+3 \cdot A A O D$ & 3 & 7.8 & 8.1 & 3 & 6.6 & 8.2 \\
\hline
\end{tabular}
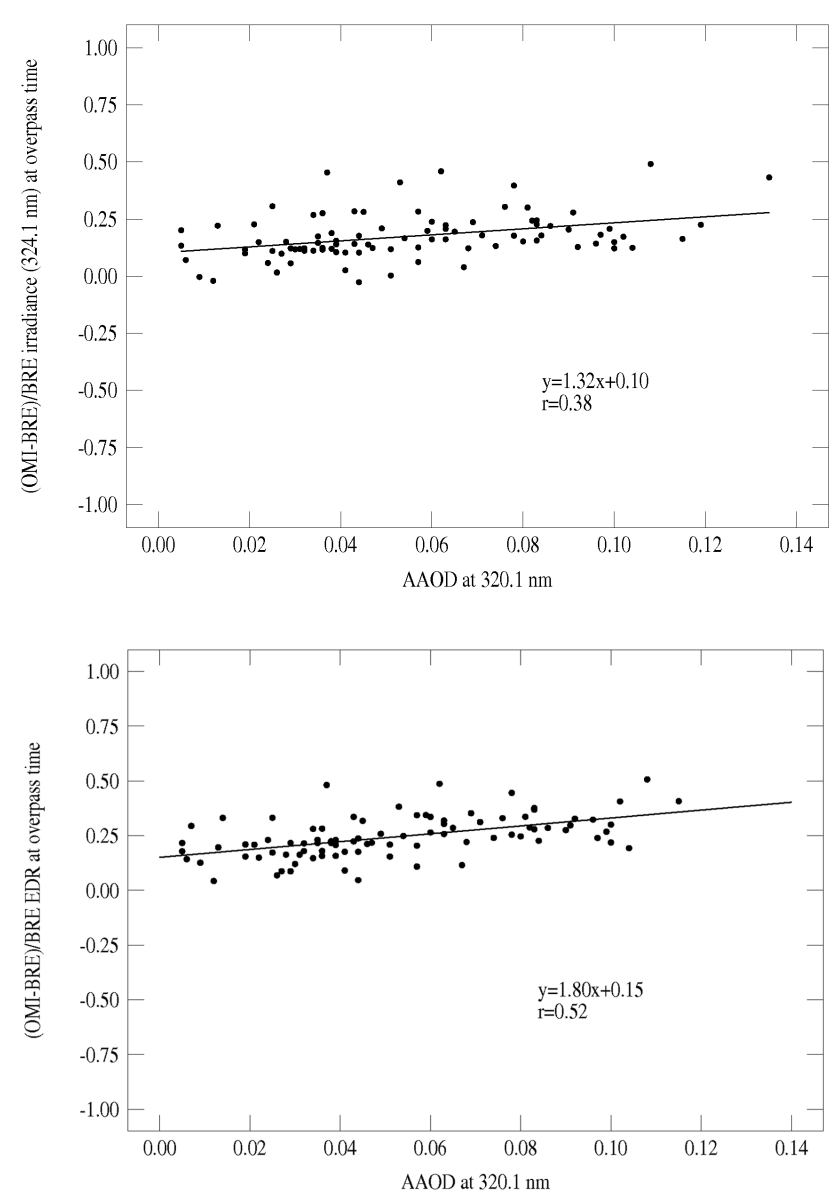

Fig. 3. (OMI-Brewer)/Brewer irradiance at $324 \mathrm{~nm}$ (upper panel) and EDR (lower panel) versus AAOD at $320 \mathrm{~nm}$ at OMI overpass time. The black line is the regression line. 
In the second method, the SZA dependence was taken into account. Indeed, the effect of an aerosol absorbing layer may lead to higher UV attenuation at higher SZAs due to the increased optical path of the solar photons through this layer. The slant absorption optical depth (AAODS) is derived as:

$\mathrm{AAODS}=\mathrm{AAOD} \cdot \cos (\mathrm{SZA})$

The slope $S$ of linear regression was determined using AAODS values.

Method 3: Krotkov et al. (2005) proposed a correction factor derived for Washington DC (USA) area with a fixed slope $S=3$ which was also applied at Rome data, being both locations classified as urban sites.

The corrected OMI UV irradiances at $324.1 \mathrm{~nm}$ and EDR at overpass time have been derived by means of the three methods described above, using the retrieved AAOD.

The results are shown in Table 1. All methods lead to reduce the bias between OMI and ground-based data. The correction of OMI overpass UV irradiance at $324.1 \mathrm{~nm}$ is here analysed in detail. If no correction was applied $\left(C_{A}=1\right)$, the mean positive bias, obtained taking into account the clear sky days for which AAOD retrievals are available within $15 \mathrm{~min}$ from the OMI overpass, is $17.7 \%$ with a standard deviation (SD) of $10.2 \%$.

If Method 1 is applied, the average value of $C_{A}$ is 0.93 taking into account the AAOD mean values with a slope of 1.32 , (upper panel in Fig. 3). The mean positive bias is reduced to $9.9 \% \pm 9.1 \%$.

If Method 2 is applied, a new slope of 1.64 per unit of AAODS was obtained. Therefore the average correction is $C_{A}=0.90$ (assuming the mean AAODS value) which leads to a larger reduction of the bias value to $5.8 \% \pm 7.4 \%$.

Following the correction methodology proposed by Krotkov et al. (2005), the average correction factor becomes $C_{A}=0.87$ and the bias value decreases to $1.6 \%$ with a larger standard deviation $(9.7 \%)$. It has to be noticed that the $+3 \%$ difference of Rome instrument with Qasume spectroradiometer, observed in 2008, can lead to a systematic overestimation of SSA that can slightly affect also the OMI comparison results.

For the EDR data at overpass time, the mean positive bias is $25.0 \% \pm 10.7 \%$ when no correction was applied. When Method 1 (AAOD data) was applied with the regression slope value of 1.8 (lower panel in Fig. 3) or when Method 2 (AAODS data) was applied with the slope value equal to 2.05 (not shown), the average value of $C_{A}$ is 0.91 . If the slope value $S=3$ was used (Method 3 ) the average $C_{A}$ is 0.86 . Depending on the correction methodology the bias value decreases from $25 \%$ to $8 \%$ (Table 1 ).

These results are similar to those obtained by Kazadzis et al. (2009) for Thessaloniki, confirming that above values can be used for urban areas characterized by similar aerosol properties.

If the AAOD mean of dataset was used for the correction, the bias is not significantly affected (the variation in the bias
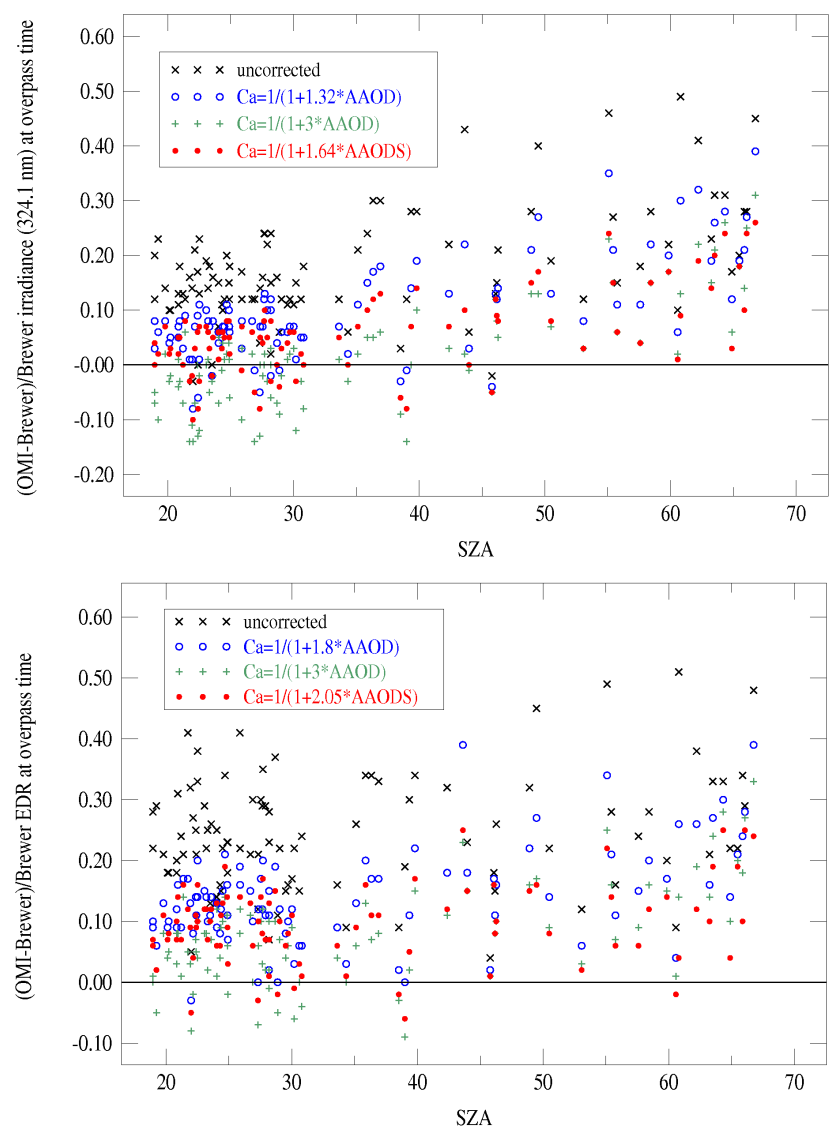

Fig. 4. (OMI-Brewer)/Brewer irradiance at $324.1 \mathrm{~nm}$ (top) and EDR (bottom) versus SZA at OMI overpass time. Black symbols indicate the original data; blue circles, red dots and green crosses represent, respectively, the results of the corrections \#1, 2 and 3 described in the text. As reference the line $\mathrm{y}=0$ is plotted.

values is lower than 1 percentage point) with respect to the previous corrections, but the standard deviations get slightly worse.

Thus, if only climatological AAOD values are available, a constant correction factor value can be applied even if the actual variability in AAOD cannot be assessed. Similar correction values were obtained for OMI UV dataset at noon time (see Table 1).

Figure 4 shows the ratio (OMI-Brewer)/Brewer for the different levels of correction as a function of SZA, taking into account irradiance at $324.1 \mathrm{~nm}$ (upper panel) and EDR (lower panel). Methods 2 and 3 provide the best correction approaches. In particular, in the latter the bias decreases significantly while the former reduces the larger relative differences at higher SZAs, decreasing the standard deviation values (Table 1).

The scatterplots OMI versus Brewer irradiance at $324 \mathrm{~nm}$ and EDR at overpass are shown in Figs. 5 and 6, respectively. Both Methods 2 and 3 were used to correct OMI UV original 


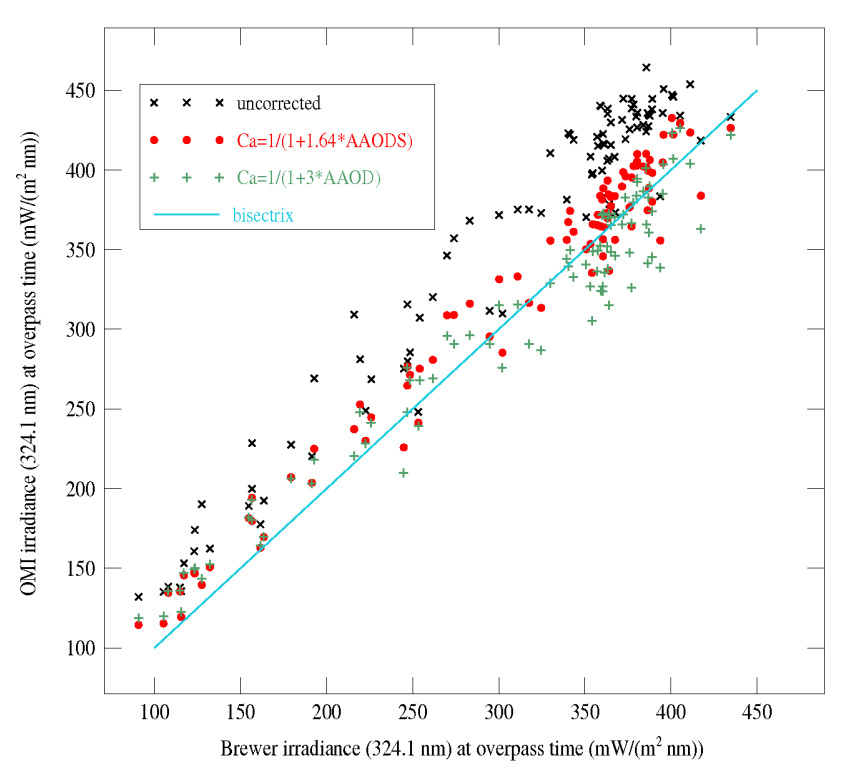

Fig. 5. OMI vs Brewer irradiance at $324.1 \mathrm{~nm}$ at overpass time scatterplot. The red dots and green crosses represent the results of the corrections \#2 and 3 described in the text. As reference the line $y=x$ is shown (light blue line).

data. After applying the corrections, the OMI UV data result closer to the bisectrix. The results of the comparisons confirm that there is still a remaining positive bias not explained by the aerosol effect (Table 1). This can be partly related to the OMI sub-pixel variability of aerosol optical properties and thus of UV irradiances (Weihs et al., 2008). Furthermore, the fact that OMI overpasses and ground based (GB) UV measurements are not exactly synchronous can lead to an increased uncertainty in OMI-ground based comparison results.

\section{Conclusions}

An indirect method for determining the effective SSA in the UV region by comparing the Brewer global irradiance measurements with model calculations was applied to Rome site. The UVSPEC radiative transfer model, initialised with the measured values of total ozone and AOD at $320.1 \mathrm{~nm}$, was used to calculate the global UV irradiance. The SSA values for which the modeled and measured irradiances agree to better than $1 \%$, were determined at different solar zenith angles during the day. It was found that this methodology provides less uncertain results when high aerosol load cases were selected. The uncertainties of the measurements together with the modelling and the AOD retrieval uncertainties contribute to the overall uncertainty in estimating of the SSA value. The AAODs were derived from simultaneous SSA and AOD data from January 2005 to June 2008. The monthly means of SSA and AAOD at $320.1 \mathrm{~nm}$ were derived. The SSA and

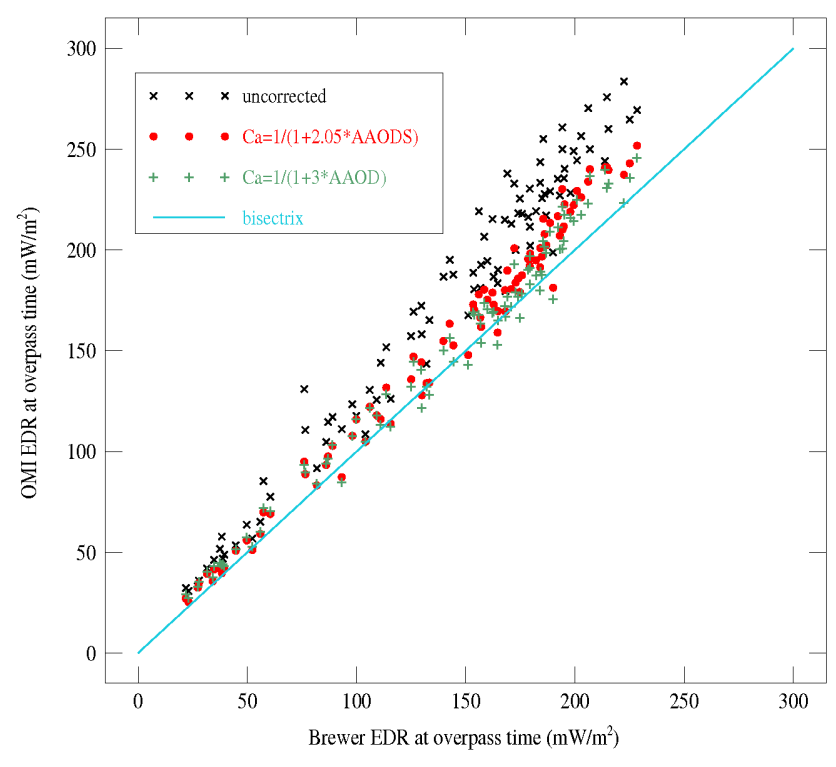

Fig. 6. OMI vs Brewer EDR at overpass time scatterplot. The red dots and green crosses represent the results of the corrections \#2 and 3 described in the text. As reference the line $y=x$ is shown (light blue line).

AAOD averages over the period study are $0.80 \pm 0.08$ and $0.056 \pm 0.028$, respectively.

The SSA and AAOD monthly means showed a significant variability within each month; it can be observed a seasonal variation in SSA, with lowest values in winter and increasing in summer and in early autumn. Otherwise, there is not such a clear seasonal variability in AAOD monthly means.

AAOD retrievals derived at Rome site were also used to quantify the error in OMI surface UV estimates due to aerosol absorption effect. OMI and Brewer UV irradiance $(324.1 \mathrm{~nm})$ and EDR measurements under clear sky conditions for the period January 2005-June 2008, were compared as a function of absorbing aerosol optical depth, which are not included in the OMI UV algorithm. Three methods, based on AAOD retrievals at $320.1 \mathrm{~nm}$, were used in order to investigate on the effect of absorbing aerosols on OMI UV data. All methods led to an improvement of OMI-GB comparisons. Results showed that for both irradiance at $324.1 \mathrm{~nm}$ and EDR data, the correction factor $C_{A}$ reduced most of the observed overestimation, with a reduction of the bias by 10 15 percentage points. $C_{A}$ values obtained at Rome site can vary between 0.86 and 0.91 , depending on the correction methodology. Such values are comparable to those obtained by Kazadzis et al. (2009) at Thessaloniki, Greece. The lowest averaged bias was obtained using method 3, which could be suggested as a proper correction procedure. On the other hand, method 2 produced better results at higher SZAs where the effect of the absorbing aerosols may lead to higher UV attenuation due to the increased optical path. Anyway, it is out 
of scope of this work to choose the best correction to be used. This still requires additional validation studies.

Similar results were obtained correcting OMI UV data at noon time; thus, the absorbing aerosol effect explains the larger part of the bias also for OMI data at noon time.

There is still a remaining positive bias not explained by the aerosol effect, especially when EDR data were taken into account, a small positive bias not related to aerosol absorption was found. A possible explanation for this could be the fact that in cloudless cases, absorbing aerosols attenuate also the reflected irradiance from the ground. That could lead to a small underestimation of reflectivity resulting in a small atmosphere transmittance overestimation. An additional reason can depend on the OMI sub-pixel variability of aerosol optical properties. Furthermore, the fact that OMI overpasses and ground-based UV measurements are not exactly synchronous can lead to an increased uncertainty in comparison results. Further reasons regarding the remaining differences in EDR could result from the differences between OMI and ground-based total ozone amounts and to the fact that the calculated slopes for SSA at $324 \mathrm{~nm}$ using AOD at $320 \mathrm{~nm}$ could be slightly different due to the enhanced absorption and larger AOD at lower UVB wavelengths. Additional uncertainties can be due to the fact that in EDR the non-measured part of UV-A band (wavelength longer than $325 \mathrm{~nm}$ ) are estimated applying weighting coefficients to the irradiance at $324 \mathrm{~nm}$ (Fioletov et al., 2004). In addition the effect of gas absorption like $\mathrm{NO}_{2}$, not included in the correction, can be another possible reason of OMI overestimation mainly in urban locations (Arola et al., 2009).

Finally when the climatological mean values of AAOD were included in the methodologies, correction values comparable to those retrieved from actual AAOD measurements, were obtained. Thus, this correction methodology can be reliably applied also in different urban sites, if either climatological or actually measured AAOD values are available.

Acknowledgements. This study was carried out in the framework of the COST Action 726 (Long term changes and climatology of UV radiation over Europe). The authors are grateful to Aura Validation Data Center (NASA) for providing OMI data. The figures were drawn using the Mgraph package developed at LOA by L. Gonzalez and C. Deroo (http://www-loa.univ-lille1.fr/Mgraph).

Edited by: A. Hofzumahaus

\section{References}

Anderson, G., Clough, S., Krneizys, F., Chetwynd, J., and Shettle, A.: AFGL atmospheric constituent profiles (0-120 km), Technical Report AFGL-Tr-86-110, Air Force Geophysics Laboratory, Hanscom Air Force Base, Bedford, MA, 1986.

Arola, A., Kazadzis, S., Krotkov, N., Bais, A., Groebner, J., and Herman, J. R.: Assessment of TOMS UV bias due to absorbing aerosols, J. Geophys. Res., 110, D23211, doi:10.1029/2005JD005913, 2005.
Arola, A., Kazadzis S., Lindfors, A., Krotkov, N., Kujanpää, J., Tamminen, J., Bais, A., di Sarra, A., Villaplana, J. M., Brogniez, C., Siani, A. M., Janouch, M., Weihs, P., Webb, A., Koskela, T., Kouremeti, N., Meloni, D., Buchard, V., Auriol, F. , Ialongo, I., Staneck, M., Simic, S., Smedley, A., and Kinne, S.: A new approach to correct for absorbing aerosols in OMI UV, Geophys. Res. Lett., 36, L22805, doi:10.1029/2009GL041137, 2009.

Bais, A. F., Kazadzis, S., Balis, D., Zerefos, C., and Blumthaler, M.: Correcting global solar ultraviolet spectra recorded by a Brewer spectroradiometer for its angular response error, Appl. Opt., 37, 6339-6344, 1998.

Bais, A., Kazantzidis, A., Kazadzis, S., Balis, D. S., Zerefos, C. S., and Meleti, C.: Deriving an effective aerosol single scattering albedo from spectral surface UV irradiance measurements, Atmos. Environ., 39(6), 1093-1102, 2005.

Casale, G. R., Meloni, D., Miano, S., Palmieri, S., Siani, A. M., and Cappellani, F.: Solar UV irradiance and total ozone in Italy: fluctuations and trend, J. Geophys. Res., 105, 4895-4901, 2000.

Charlson, R. J., Schwartz, S. E., Hales, J. M., Cess, R. D., Coakley, J. A., Hansen, J. E., and Hofmann, D. J.: Climate forcing by anthropogenic aerosols, Science, 255, 423-430, 1992.

Cheymol, A., Gonzalez Sotelino, L., Lam, K. S., Kim, J., Fioletov, V., Siani, A. M., and De Backer, H.: Intercomparison of Aerosol Optical Depth from Brewer Ozone spectrophotometers and CIMEL sunphotometers measurements, Atmos. Chem. Phys., 9, 733-741, 2009, http://www.atmos-chem-phys.net/9/733/2009/.

Chou, M. D., Lin, P. H., Ma, P. L., and Lin, H. J.: Effects of aerosols on the surface solar radiation in a tropical urban area, J. Geophys. Res., 111, D15207, doi:10.1029/2005JD006910, 2006.

CIE (Commission Internationale d'Eclairage): Research note: A reference action spectrum for ultraviolet induced erythema in human skin, C.I.E. J., 6, 17-22, 1987.

Elterman, L.: UV, visible, and IR attenuation for altitudes to $50 \mathrm{~km}$, Technical Report AFCRL-68-0153, Air Force Geophysics Laboratory, Hanscom Air Force Base, Bedford, MA, USA, 1968.

Fioletov, V. E., Kerr, J. B., Wardle, D. I., Krotkov, N., and Herman, J. R.: Comparison of Brewer ultraviolet irradiance measurements with total ozone mapping spectrometer satellite retrievals, Opt. Eng., 41, 3051-3061, 2002.

Fioletov, V. E., Kimlin, M. G., Krotkov, N., McArthur, L. J. B., Kerr, J. B., Wardle, D. I., Herman, J. R., Meltzer, R., Mathews, T. W., and Kaurola, J.: UV index climatology over the United States and Canada from ground-based and satellite estimates, J. Geophys. Res., 109, D22308, doi:10.1029/2004JD004820, 2004.

Forster, P. M., Shine, K. P., and Webb, A. R.: Modelling ultraviolet radiation at the Earths surface. Part II: Model and instrument comparison, J. Appl. Meteorol., 34, 2426-2439, 1995.

Gröbner, Blumthaler M. and Ambach W.: Experimental investigation of spectral global irradiance measurement error due to a non ideal cosine response, Geophys. Res. Lett., 23(18), 2493-2496, 1996.

Gröbner, J., Schreder, J., Kazadzis, S., Bais, A. F., Blumthaler, M., Görts, P., Tax, R., Koskela, T., Seckmeyer, G., Webb, A. R., and Rembges, D.: Traveling reference spectroradiometer for routine quality assurance of spectral solar ultraviolet irradiance measurements, Appl. Opt., 44, 5321-5331, 2005.

Herman, J. R., Krotkov, N., Celarier, E., Larko, D., and Labow, G.: Distribution of UV radiation at the Earth's surface from TOMS- 
measured UV-backscattered radiances, J. Geophys. Res., 104, 12059-12076, 1999.

Hulsen, G.: Report on Protocol of the intercomparison at the University of Rome La Sapienza, Italy on June 03 to 06, 2008 with the traveling reference spectroradiometer Qasume from PMOD/WRC, 2008.

Ialongo, I., Casale, G. R., and Siani, A. M.: Comparison of total ozone and erythemal UV data from OMI with ground-based measurements at Rome station, Atmos. Chem. Phys., 8, 32833289, 2008, http://www.atmos-chem-phys.net/8/3283/2008/.

Ialongo, I.: Surface UV radiation, total ozone and aerosol monitoring by means of satellite and ground-based instruments at Rome, $\mathrm{PhD}$ thesis, Physics Dept., Sapienza University of Rome, Italy, 131 pp., 2009.

Kazadzis, S., Bais, A., Arola, A., Krotkov, N., Kouremeti, N., and Meleti, C.: Ozone Monitoring Instrument spectral UV irradiance products: comparison with ground based measurements at an urban environment, Atmos. Chem. Phys., 9, 585-594, 2009, http://www.atmos-chem-phys.net/9/585/2009/.

Kazantzidis, A., Balis, D. S., Bais, A. F., Kazadzis, S., Galani, E., Kosmidis, E., and Blumthaler, M.: Comparison of model calculations with spectral UV measurements during the SUSPEN campaign: the effect of aerosols, J. Atmos. Sci., 58, 1529-1539, 2001.

Kerr, J. B.: Observed dependencies of atmospheric UV radiation and trends. In Solar ultraviolet radiation, modelling, measurements and effects, 1, 65-84, Springer-Verlag, Berlin, Germany, 1997.

Kerr, J. B.: Understanding the factors that affect surface UV radiation, Ultraviolet Ground and Space based measurements, models and effects III, edited by: Slusser, J. R., Herman, J. R., and Gao, W., Proc. SPIE, 1-14, 2003.

Krotkov, N. A., Bhartia, P. K., Herman, J. R., Fioletov, V., and Kerr, J.: Satellite estimation of spectral surface UV irradiance in the presence of tropospheric aerosols: 1. Cloud-free case, J. Geophys. Res., 103(D8), 8779-8793, 1998.

Krotkov, N., Herman, J. R., Bhartia, P. K., Seftor, C., Arola, A., Kaurola, J., Kalliskota, S., Taalas, P., and Geogdzhayev, I. V.: Version 2 total ozone mapping spectrometer ultraviolet algorithm: Problems and enhancements, Opt. Eng., 31, 3028-3039, 2002

Krotkov, N., Bhartia, P. K., Herman, J. R., Slusser, J., Scott, G., Labow, G., Vasilkov, A., Eck, T., Dubovik, O., and Holben, B., Aerosol UV absorption experiment (2002-04): 2. absorption optical thickness, refractive index, and single scattering albedo, Opt. Eng., 44(4), 041005, 2005.

Krzyscin, J. W. and Pulchalski, S.: Aerosol impact on the surface UV radiation from the ground-based measurements taken at Belsk, Poland, 1980-1996, J. Geophys. Res., 103(D13), 1617516181, 1998.

Kylling, A., Bais, A. F., Blumthaler, M., Schreder, J., and Zerefos, C. S.: The effect of aerosols on solar UV irradiances during the PAUR campaign, J. Geophys. Res., 103(D20), 26051-26060, 1998.

Levelt, P. F., van den Oord, G. H. J., Dobber, M. R., Mälkki, A., Visser, H., de Vries, J., Stammes, P., Lundell, J., and Saari, H.: The Ozone Monitoring Instrument, IEEE Trans. Geo. Rem. Sens, 44, 5, 1093-1101, 2006.

Madronich, S., McKenzie, R. L., Björn, L. O., and Caldwell, M.
M.: Changes in biologically active ultraviolet radiation reaching the Earth's surface, J. Photochem. Photobiol., 46, 5-19, 1998.

Mallet, M., Van Dingenen, R., Roger, J. C., Despiau, S., and Cachier, H.: In situ airborne measurements of aerosol optical properties during photochemical pollution events, J. Geophys. Res., 110, D03205, doi:10.1029/2004JD005139, 2005.

Mayer, B., Seckmeyer, G., and Kylling, A.: Systematic long-term comparison of spectral UV measurements and UVSPEC modeling results, J. Geophys. Res., 102(D7), 8755-8767, 1997.

Mayer, B. and Kylling, A.: Technical note: The libRadtran software package for radiative transfer calculations - description and examples of use, Atmos. Chem. Phys., 5(7), 1855-1877, 2005.

McKenzie, R. L., Connor, B. J., and Bodeker, G. E.: Increased summertime UV observed in New Zealand in response to ozone loss, Science, 285, 1709-1711, 1999.

Meleti, C. and Cappellani, F.: Measurements of aerosol optical depth at Ispra: analysis of the correlation with UV-B, UV-A, and total solar irradiance, J. Geophys. Res., 105, 4971-4978, 2000.

Meloni, D., Casale, G. R., Siani, A. M., Palmieri, S., and Cappellani, F.: Solar UV Dose Patterns in Italy, Photochem. Photobiol., 71, 6, 681-690, 2000.

Meloni, D., Marenco, F., and di Sarra, A. G.: Ultraviolet radiation and aerosol monitoring at Lampedusa, Italy, Ann. Geophysics, 46(2), 373-383, 2003.

Modesti, S.: UV irradiance modeling at Rome under clear sky and cloudy conditions, M.S. thesis, Physics Dept., Sapienza University of Rome, Italy, 116 pp., 2008.

Petters, J. L., Saxena, V. K., Slusser, J. R., Wenny, B. N., and Madronich, S.: Aerosol single scattering albedo retrieved from measurements of surface UV irradiance and a radiative transfer model, J. Geophys. Res., 108(D9), doi:10.1029/2002JD002360, 2003.

Reuder, J. and Schwander, H.: Aerosol effects on UV radiation in nonurban regions, J. Geophys. Res., 104, 4065-4077, 1999.

Ruggaber, A., Dlugi, R., and Nakajima., T.: Modelling radiation quantities and photolysis frequencies in the troposphere., J. Atmos. Chem., 18, 171-210, 1994.

Schwander, H., Koepke, P., and Ruggaber, A.: Uncertainties in modelled UV irradiances due to limited accuracy and availability of input data, J. Geophys. Res., 102, 9419-9429, 1997.

Schwartz, S. E., Arnold, F., Blanchet, J. P., Durkee, P. A., Hoffman, D. J., Hoppel, W. A., King, M. D., Lacis, A. A., Nakajima, T., Ogren, J. A., Toon, O. B., and Wendisch, M.: Group report: in: Connections between aerosol properties and forcing and climate, edited by: Charlson, R. J. and Heintzenberg, J., Aerosol Forcing of Climate, J. Wiley \& Sons, New York, USA, 251-277, 1995.

Schwartz, S. E. and Andreae, M.: Uncertainty in climate change caused by aerosols, Science, 272, 1121-1122, 1996.

Sellitto, P., di Sarra, A., and Siani, A. M.: An improved algorithm for the determination of aerosol optical depth in the ultraviolet spectral range from Brewer spectrophotometer observations, J. Opt. A: Pure and Applied Optics, 8, 849-855, 2006.

Siani, A. M., Benevento, G., and Casale, G. R.: Temperature dependence of Brewer UV measurements at Rome station, Proc. The International Symposium on Optical Science and Technology, Ultraviolet Ground and Space based measurements, models and effects III, 5156, 355-366, 2003.

Spencer, J. W.: Fourier series representation of the position of the Sun, Search, 2(5), p. 172, 1971. 
Stamnes, K., Tsay, S. C., Wiscombe, W., and Jayaweera, K.: Numerically stable algorithm for discrete-ordinate-method radiative transfer in multiple scattering and emitting layered media, Appl. Opt., 27, 2502-2509, 1988.

Tanskanen, A.: Lambertian surface albedo climatology at $360 \mathrm{~nm}$ from TOMS data using moving time-window technique, in Proceedings of the XX Quadrennial Ozone Symposium, 1-8 June 2004, Kos, Greece, 2004.

Tanskanen, A., Krotkov, N. A., Herman, J. R., and Arola, A.: Surface Ultraviolet Irradiance from OMI, IEEE Trans. Geo. Rem. Sens., 44(5), 1267-1271, 2006.

Tanskanen, A., Lindfors, A., Maatta, A., Krotkov, N., Herman, J., Kaurola, J., Koskela, T., Lakkala, K., Fioletov, V., Bernhard, J., McHenzie, R., Kondo, Y., O’Neill, M., Slaper, H., den Outer, P., Bais, A. F., and Tamminen, J.: Validation of daily erythemal doses from OMI with ground-based UV measurement data, J. Geophys. Res., 112, D24S44, doi:10.1029/2007JD008830, 2007.
Weihs, P., Blumthaler, M., Rieder, H. E., Kreuter, A., Simic, S., Laube, W., Schmalwieser, A. W., Wagner, J. E., and Tanskanen, A.: Measurements of UV irradiance within the area of one satellite pixel, Atmos. Chem. Phys., 8, 5615-5626, 2008, http://www.atmos-chem-phys.net/8/5615/2008/.

WMO (World Meteorological Organization): Scientific Assessment of Ozone Depletion: 2006, Global Ozone Research and Monitoring Project, 47, World Meteorological Organization Report, Geneva, Switzerland, 2007.

Zerefos, C. S., Meleti, C., Bais, A. F., and Lambros, A.: The recent UVB variability over southeastern Europe, J. Photochem. Photobiol., 31, 15-19, 1995. 